\title{
backstory
}

\section{Into the deep}

\section{In an attempt to assess the factors controlling the rates of glacial melt in West Antarctica, Adrian Jenkins and colleagues found themselves waiting anxiously for their submersible, Autosub3, to return from under an ice shelf.}

\section{What was the objective of the work?} We wanted to determine how warm ocean waters flow beneath the floating ice shelf of Pine Island Glacier. Our objective was to understand the processes driving the thinning and acceleration of the glacier that has been observed over the past two decades. We used an autonomous underwater vehicle (AUV) to take measurements and monitor the processes taking place beneath the ice shelf. Specifically, we wanted to map the seabed topography, to map the underside of the ice shelf and to observe where heat is transferred from the warm inflowing water to the cooler outflow.

Why did you choose this location for the fieldwork?

Pine Island Glacier is one of the largest outlet glaciers of the Antarctic ice sheet and the one that is changing most rapidly at present. Understanding how the ocean might be driving the present phase of accelerated melting and thinning is critical to predicting the glacier's future contribution to global sea level.

\section{Did you encounter any difficulties?} It took a decade of effort to collect these data. The research programme began in 1999. A cruise to the Amundsen Sea in 2003 carried an early version of the AUV, but access to Pine Island Glacier was prevented because of sea ice. A new AUV was built, called the Autosub3, but extensive testing was required to prove that the vehicle was reliable enough for dispatch beneath permanent ice cover. Thus, in 2007, a joint UK/US cruise had to go ahead without the new AUV. In January 2009 everything came together. Autosub3 was finally deemed fit for sub-ice operation, the ship was ready, and perfect sea-ice-free

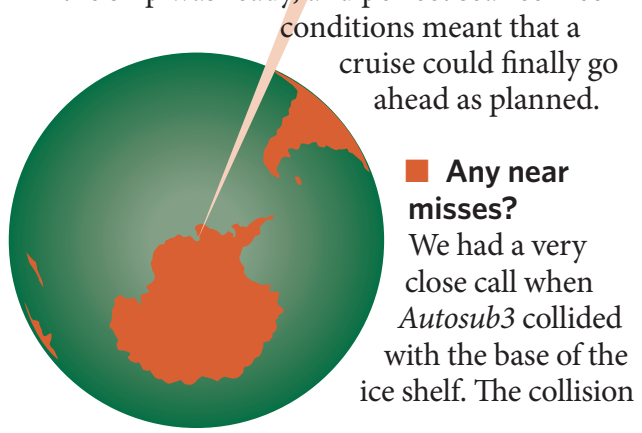

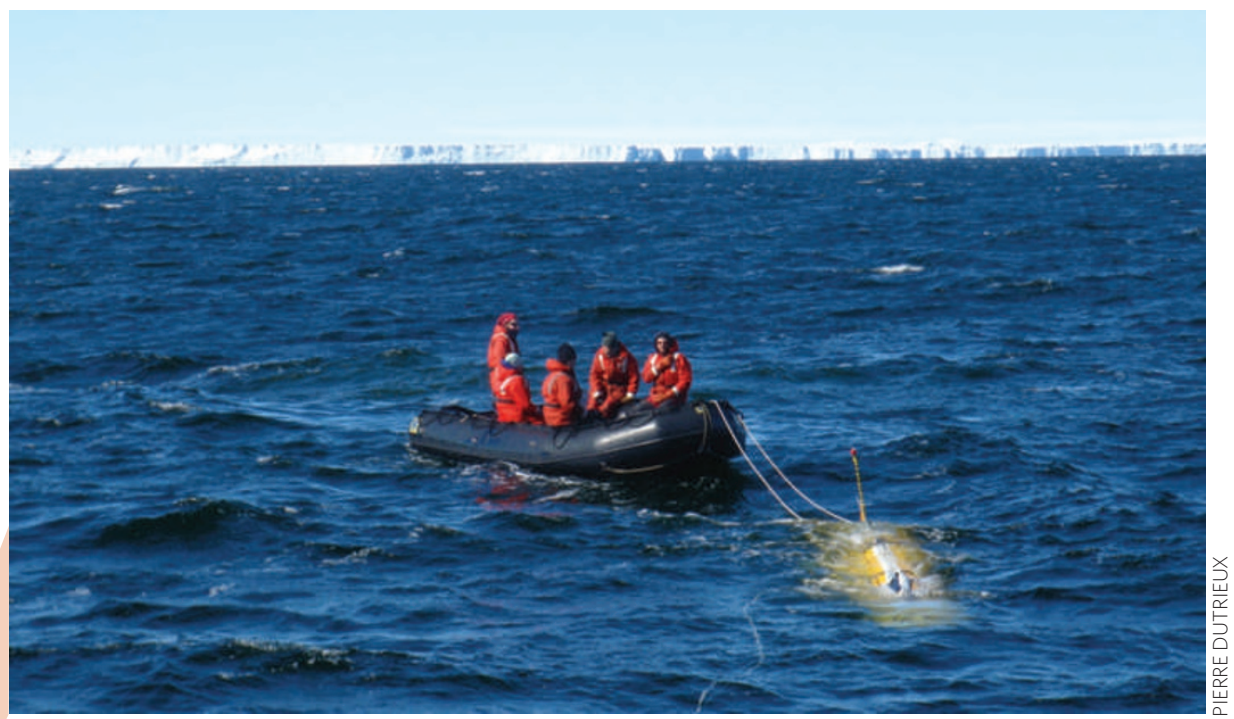

The crew setting up safe recovery of Autosub3 after its second successful mission beneath the floating ice tongue of Pine Island Glacier (in the background).

happened $50 \mathrm{~km}$ away from the open water, as the AUV ascended into a large crevasse and hit the wall. While searching for a route out of the crevasse, it scraped along the ice wall for eight minutes, before eventually breaking free and heading for the recovery point. The nose of the submersible was damaged, but most of the sensors continued to record good data. Following repairs, Autosub3 was back in the water two days later.

\section{What was the highlight of the} expedition?

There were six highlights; the moments at the end of each mission when we remade contact with Autosub3. Following each launch we had no contact with the AUV for twenty to thirty hours. The ship would work elsewhere, before returning to the recovery point to listen for Autosub3's acoustic signal, which is given out once every six minutes. The time spent waiting for the first signal was incredibly tense. We knew that up to six minutes of silence was fine, but any more could mean that we would never see the GBP1 million AUV again. The sense of relief when contact was made, followed by the excitement of seeing the first data recorded beneath Pine Island Glacier, was euphoric.
Did the trip give you any ideas for future research projects?

The new data have transformed our understanding of what might be driving the present changes in Pine Island Glacier. Our discovery of a submarine ridge on which the glacier was once grounded suggests that the changes we see now are part of a longer-term process that started many decades ago at least. We now plan to use a regional ocean model to investigate the possible longer-term ocean forcing on the glacier. We have also been discussing a design concept for a future AUV that would avoid the problems associated with seasonal access to the glacier. The submersible would be deployed by ship in the summer months to run a series of pre-programmed missions, interspersed by periods of 'hibernation' to conserve battery power, before being retrieved the following summer. This could provide insight into the processes that take place during the currently data-sparse polar winter.

This is the Backstory to the work by Adrian Jenkins and colleagues, published on page 468 of this issue. 